\title{
A Projective Geometry for Separation Experiences
}

\author{
F. Gordon Greene \\ Sacramento, $C A$
}

\begin{abstract}
$A B S T R A C T$ : I present a projective geometry for out-of-body "separation experiences," built up out of a series of higher space analogies and resulting diagrams. The model draws upon recent understandings of cosmic symmetries linking relativity theory to quantum physics. This perspective is grounded inside a more general hyperspace theory, supposing that our three dimensional space is embedded within a hierarchy of higher dimensions. Only the next higher space, the fourth dimension, is directly utilized in this exposition. At least two degrees of consciousness expansion are identified as prerequisites to a comprehensive phenomenological taxonomy of ecstatic outof-body, near-death, and mystical/visionary experiences. The first assumes a partial spatiotemporalization of consciousness into a fractional domain located between three and four dimensions. The second assumes a complete spatiotemporalization into four dimensions. Partial expansions are associated with separation experiences and with thematically related activities of a seeming paranormal character. Complete expansions are associated with "timeless" life panoramas and with excursions into hyperphysical realms. The paper concentrates on partial expansions, in analyzing the psychodynamics underlying, and ostensive paranormal activities accompanying, separation experiences.
\end{abstract}

Higher space theories for ecstatic other world visions, and for related activities of a seeming paranormal character, have long intrigued parapsychologists. Among the ostensive psychic happenings so explained are such things as clairvoyance, remote viewing, telepathy, teleportation, psychokinesis (PK), psychic healing, levitation, and precognition (Broad, 1969; Dunne, 1927; Hinton, 1904; Krippner and Villoldo, 1976; Lombroso, 1909; Luttenberger, 1977; Nash, 1963;

F. Gordon Greene is a free-lance writer whose principal interests have been parapsychology, religion, and metaphysics. Reprint requests should be addressed to Mr. Greene at P.O. Box 163683, Sacramento, CA 95816. 
Rauscher, 1980; Renninger, 1977; Rosen, 1983; Smith, 1920; Smythies, 1967; Tinoco, 1982; White and Krippner, 1977; Whiteman, 1967; Zollner, 1881). Such theories have also been advanced to account for expanded states of consciousness, apparitions and materializations of the dying and the dead, spirit possessions, hauntings, and afterlife abodes (Bragdon, 1916; Capel, 1979, 1979; Couliano, 1991; Greene and Krippner, 1990; Hart, 1953; Hart and associated collaborators, 1956; McKenna, 1992; McLaughlin, 1977, 1986; Murphy, 1992; Ouspensky, 1923; Price, 1939, 1953; Wenzl, 1957; Whiteman, 1961, 1986, Woodhouse, 1990). Theories of higher dimensions or hyperspaces, then, are nothing new in parapsychology or in what has come to be called consciousness research. They have also figured in the emerging study of near-death experiences (NDEs) (Becker, 1993; Cox-Chapman, 1995; Gallup and Proctor, 1982; Greene, 1981; Ring, 1980; Sharp, 1995).

What has yet to be determined is how hyperspace theory specifically models out-of-body "separation experiences." In this paper, I propose to do just this, while integrating an experiential explanation for out-of-body experiences (OBEs) into a more general hyperspace theory of the paranormal. While the term hyperspace often refers to any space of more than three dimensions, throughout most of the paper, the term refers specifically to the fourth dimension. Before elucidating the theory, let us consider various of the conceptual inadequacies of $\mathrm{OBE}$ theories currently dominating discussions of the ecstatic and the paranormal. This will lead us, in turn, to consider the need for a new understanding of OBEs and for related ecstatic/dream/visionary experiences.

\section{Theories of Out-of-Body Experiences}

Superficially considered, sensations of consciousness separating from the physical body would seem unrelated to hyperspace. Out-ofbody experiences would appear to support another reality conception. Human consciousness, housed either inside a "subtle vehicle" or in an entirely disembodied condition, would seem capable of existing inside the physical universe yet outside the physical body. Many parapsychologists and near-death researchers have advocated some form of this extrasomatic view of OBEs (Becker, 1983a, 1983b; Moody and Perry, 1988; Osis, 1978; Ring, 1980; Rogo, 1973; Sabom, 1982; Tart, 1978). However, OBE detection studies conducted between the early 1970 s and early 1980 s failed to confirm the existence of this 
out-of-body aspect. Occasional tantalizing "hits" of debatable value and statistically weak successes were dwarfed by repeated failures to detect any facet of human nature existing outside the body (Alvarado, 1982a; Blackmore, 1982b).

In response, parapsychologists of the late 1970 s and early $1980 \mathrm{~s}$ began favoring a psychological approach to explain OBEs (Blackmore, 1982a; Ehrenwald, 1978; Gabbard and Twemlow, 1984; Irwin, 1985; Palmer, 1978). In the psychological view, out-of-body sensations are illusory. Voyagers have unknowingly entered into the inner spaces of dreams and visions. During OBEs, they simply mistake these inner journeys for actual excursions outside the body. If there is anything paranormal about OBEs, the presumption is that this involves some form of brain-dependent hallucination, augmented by psychic or psi phenomena. A major problem with the psychological approach is that it fails to provide a rational explanation for paranormal activities traditionally associated with OBEs. Another difficulty involves the as-yet-incomprehensible relationship between the inner spaces of the mind and the space of external reality. Where, then, are these mind spaces-if anywhere at all-and what is their relationship to physical space? Perhaps only when these mysteries are better understood will OBEs really begin to make sense. Conversely, illuminating the true meaning of OBEs might bring with it a far greater understanding of the mysterious relationship between mind and matter.

Whatever the relationship may be between "inner" and "outer" space, and whether or not it will ever be understood, remains unknown. What is known, however, is that belief in the paranormality, or psi-conduciveness, of OBEs remains widespread. Anecdotal reports and experimental demonstrations of OBE-related traveling clairvoyance, and of remote viewing, continue to fill the pages of a growing literature (McMoneagle, 1993; Mitchell, 1981; Targ and Harary, 1984). Occasional reports of OBE-related PK may also be found in psychic literature (Rogo, 1978b). More incredible yet are the relatively rare but persistent reports of phantasmal intrusions, by ecstatic voyagers, into the public space of physical reality (Becker, 1993; Hart 1954; Irwin, 1985).

An ecstatic voyager, perceived as a (presumably) intangible apparition, may be seen, or otherwise sensed, by a human observer, at a site far removed from that of the voyager's physical body. This is at the time that this voyager sensed that he or she was paranormally present at that distant location. Even more rare, yet persistent, are reports of bilocation. Ecstatic voyagers appear to materialize a second 
physical body, at a location far removed from that of their original physical body. Such a voyager might even seem to interact physically with one or more human witnesses at this second location before suddenly vanishing (Atwater, 1994; Bremmer, 1983; Grosso, 1992; Mitchell, 1981; Osis, 1978). In classical antiquity and in "timeless" India, bilocation has long been associated with spiritual sages. In the Roman Catholic tradition, the ostensive power to bilocate is considered a sign of sainthood.

Many researchers, locked into the presumption that they must choose between the extrasomatic and psychological alternatives, have become impaled on the horns of a dilemma. The extrasomatic hypothesis, so difficult if not impossible to experimentally confirm, offers an easily conceivable rationale for a diverse number of paranormal happenings traditionally linked to OBEs. In this view, some aspect of human consciousness actually separates from the physical body and travels to distant physical world locations OBErs believe they have visited. The "disembodied" variant could explain why the vast majority of OBErs report that they are invisible to human observers and to other detection instruments at target sites these voyagers believe they have visited. If OBErs are utterly intangible, consisting of nothing but "pure consciousness," this might also explain OBE reports of passing through solid walls and other material obstructions.

However, other OBE reports of paranormal incidents defy rational explanation within a disembodied context. As noted, a few OBErs claim to have moved material objects during their experiences, presumably via PK. Anecdotal reports of OBE-related PK are actually quite rare. However, reports of $P K$ eruptions occurring in the immediate vicinity of the dying are more common. Near, or sometimes precisely at the moment of death, clocks have been reported to stop inexplicably, glass has unexpectedly shattered and other strange knockings on bedroom walls or furniture have been reported. Similar ostensive displays of $\mathrm{PK}$ have long been associated with seances, hauntings and poltergeist attacks. Thus, the notion of OBE-related manifestations of PK does fit into the overall pattern of paranormal activity identified by parapsychologists.

Such an ability is difficult to conceptualize under the premise that OBErs are entirely disembodied. Possessing no material substance themselves, how could they ever touch let along move material objects? And, the ability of OBErs occasionally to manifest as apparitions may also stretch the disembodied variant beyond the bounds 
of reason. Most extraordinary of all are reports of bilocation. How could this form of materialization ever be reconciled with a disembodied view of OBEs or, even more to the point, with Western reality conceptions?

Those who favor the psychological approach avoid these difficulties by simply ignoring reports of OBE-related apparitions and bilocations. Skeptics of the paranormal need not even insert the clause that OBEs are "psi-conducive" into their perspective. Rather, OBEs and related ecstatic experience become brain-dependent hallucinations. This approach explains a particular sort of incident that has come to perplex parapsychologists. Out-of-body experiencers may sense vividly that they have extrasensorily perceived aspects of the physical world. But upon later checking to confirm their out-of-body impressions, they find that they were wrong. For example, they might seem to float up through the ceiling of a building housing their physical body and see a chimney on the roof that they later discover is not there (Gabbard and Twemlow, 1984; Rogo, 1978b). In the psychological approach, the assumption is that these experiencers were simply traveling through their own interior worlds. And, in their wanderings, they were misconstruing the subjective contents of their imaginations for the objective properties of the external world.

However, other OBE accounts and remote viewing reports, some anecdotal and some experimentally verified, of highly accurate extrasensory impressions of the external world continue to confound the paranormally curious (Alvarado, 1982b; Mitchell, 1981; Ring and Lawrence, 1993; Sabom, 1982; Sharp, 1995; Targ and Harary, 1984).

A related perplexity involves the wide range of perceived bodily forms OBErs report inhabiting. The most notable of these about which so much has been written is called the "astral double" or "etheric duplicate" (Crookall, 1960; Powell, 1927). This form, as these names imply, is often self-perceived by voyagers to be identical to the physical body in shape, size, and touch. Even the clothing worn by the physical body at the time of the separation experience is sometimes duplicated on the double. Yet, while the double may resemble the physical body in minute detail, it is widely reputed to possess additional ideoplastic properties. It can purportedly change size, shape, and density, subject at least in part to its inhabitant's will (Walker, 1974). Very occasionally, ecstatic voyagers report simultaneously occupying two or more bodies separate from and in addition to their physical body. Cases of this last sort, already explored in a previous paper (Greene, 1983), lie outside this paper's scope. 
A whole range of other bodily forms have also been described by ecstatic voyagers (Blackmore, 1982a; Green, 1968; Irwin, 1985; Rogo, 1978a). As noted by Scott Rogo (1978b), these other forms call into question the adequacy of traditional psychic and occult doctrines on subtle bodies. Experiencers sometimes describe inhabiting fluidic bodies, gaseous mists, and energy patterns seemingly diffused through greater areas of space than is the physical body or its astral double. They also report inhabiting globular forms of varying sizes and even points of light that may be "no larger than a dime." Related to this last form of sensed embodiment-if it can be called that-are the somewhat common sensations of inhabiting no body whatsoever. And yet, fairly often, "disembodied" voyagers describe themselves as occupying a specific location in space outside their physical body. How are we to make sense of these variations in bodily form all the way up to and including sensations of disembodiment? Are reports of being disembodied even intelligible? Without any sense of body boundaries between self and non-self, how would it be possible to locate one's self anywhere specifically inside the physical universe? And, lacking any receptive organ such as an eye, how could a disembodied voyager capture stimuli convertible into perceptions?

Troubled by these problems, contemporary researchers find themselves at a conceptual and theoretical impasse. How, then, are the utterly confounding phenomenological and seeming paranormal properties of OBEs to be most adequately explained? Is there any rational way to reconcile these apparently contradictory findings into a single coherent framework? Plausible answers are not to be found by forcing the reported properties of ecstatic experiences into either a purely extrasomatic or a purely psychological framework. When adopting either viewpoint, the temptation becomes too great to ignore pertinent information irreducible to that understanding. Rather, viable solutions are discovered by looking at a third alternative: hyperspace theory. Hyperspace theory is large enough, and flexible enough, to encompass all of the reported properties of OBEs and other ecstatic experiences. Hyperspace theory also provides a context for a possible solution to the mysterious relationship between "inner" and "outer" space.

In this paper, then, I present an experiential and paranormal model for separation experiences, and for related ecstatic/dream/visionary experiences. A "spatialized time" interpretation of Albert Einstein's relativity theory is integral to this discussion. Recent speculations on the possible relationship between spatialized time, 
the fourth dimension, and quantum physics are also important. Consequently, I offer some words on relativity and its possible relationship to quantum physics, before elucidating the specifics of this projective geometry.

\section{World-Lines as Hypersolids Inside Four-Dimensional Space}

In relativity theory, time becomes the fourth dimension, interchangeable in some sense with the three dimensions of space. In this new cosmic view, wrote Herman Weyl:

The scene of action of reality is not a three-dimensional space, but rather a four-dimensional world, in which space and time are linked together indissolubly. However deep the chasm may be that separates the intuitive nature of space from that of time in our experience, nothing of this qualitative difference enters into the objective worlds which physics endeavors to crystallize out of direct experience. It is a four-dimensional continuum which is neither 'space' nor 'time.' Only the consciousness that passes on in one portion of this world experiences the detached piece which comes to meet it and passes behind it as history, that is, as a process that is going forward in time and takes place in space. (Whitrow, 1972, pp. 103-104)

In relativity, our three-dimensional world becomes a subjective shadow, a lower-dimensional projection, of an objective four-dimensional world. All that truly exists is eternally present in space/time. This four-dimensional reality is parceled up into successive three-dimensional cross sections by "eternity-blind" human beings incapable of absorbing it all at once. In the words of Arthur Eddington (1958, p. 92), consciousness "invents its own serial order for the sense impressions belonging to the different view-points along the track [of space/time]." Describing the illusory nature of the three-dimensional world in relativity theory, Einstein once remarked that "the distinction between past, present, and future is only an illusion" (Davies, 1995 , p. 70). Unfortunately, human beings are trapped inside this time-bound illusion, at least in ordinary consciousness states.

Such a world-view is summed up in the statement that "all that really exists [are] world lines in space-time" (Rucker, 1977, p. 81). But what are world-lines? Edward Harrison (1984) wrote that

The birth of a child is an event. The child grows, experiences many events, then dies, and death is the last event. These events from 
birth to death when strung together form a line in . . space-andtime . . . . This life line, called a world line, shows the position in space of the person at each moment in time. (p. 140)

Similarly, George Gamow (1988/1957, p. 61) wrote: “Think of yourself as a four-dimensional figure, a kind of long rubber bar extending in time from the moment of your birth to the end of your natural life."

For those who see no relationship between Einstein's spatialized time, world-lines, and higher consciousness states, there is, perhaps, no way out of these shadows. For those who do, other possibilities emerge. Human beings possess the capacity to become more than just shadowy cross-sections of their own "timeless" world-lines. During OBEs, near-death experiences (NDEs), and other ecstatic/dream/visionary experiences, a person's consciousness may expand temporarily into this higher, infinitely more "real," fourth dimension. That person's "higher self," in other words, awakens from the "dream state" of physical reality. In the words of Janusz Slawinski (1987, p. 90), consciousness "enters another 'dimension' where space and time are fused into one reality." It was just these possibilities that inspired me to write several papers devoted to a hyperspatial interpretation of NDEs. (Greene, 1981; Greene and Krippner, 1990). During panoramic visions of life, then, some aspect of human consciousness is expanding, that is, hyperspatializing into four dimensions.

This expansion accounts not only for the timeless display of countless past experiences associated with life panoramas but also for another facet of such visions. Some life panoramas apparently include prophetic and previsionary elements, as documented by Kenneth Ring (1982, 1984) and Margot Grey (1985). Ring (1984, p. 183) observed that "It is as though the individual sees something of the whole trajectory of his life, not just past events." It comes as little surprise, then, that this level of hyperspace theory provides us with some insight into the possible workings of precognition and retrocognition (Dunne, 1927; Myers, 1903; Whiteman, 1967; Zohar, 1982). In this timeless state, also entered during dreams and visions, experiencers have direct access to events that have yet to be actualized, or have already been actualized, in the three-dimensional world.

The projective geometry introduced in this paper develops another aspect of this same hyperspace theory. Rather than considering what occurs during complete spatiotemporalizations, the present application attends to partial or incomplete expansions. Experiencers come to exist between space and hyperspace. They have expanded partially 
out of the third dimension but have not fully entered into the fourth. Three possibilities emerge out of this in-between state: experiencers may "contract" back into the third dimension, they may "expand" completely into the fourth dimension, or they may remain in this "twilight zone" state or consciousness level. They may continue to exist, then, at the edge of "eternity's shadows." Let us now explore these edges.

\section{At The Edge of Eternity's Shadows}

In ordinary consciousness, a person's "body sense" is limited to the physical organism as ordinarily perceived, that is, as extended in a space perceived to be three-dimensional. Possible extensions to this body and space, reaching beyond the physical world, remain invisible and intangible to those so grounded. The higher or four-dimensional self continues to sleep and dream the dream that "reality" is purely three-dimensional. However, when the higher self begins to awaken, a person's consciousness begins to expand out of the three-dimensional world. Mind/body awareness dilates along the world-line extending at right angles to three-dimensional space. Similarly, Collin Wilson (1988, p. 70) noted that "Peak experiences and mystical experiences are not glimpses of some ineffable, paradoxical truth, but simply a widening of our ordinary field of perception." But how, more exactly, are we to conceptualize this widening of our ordinary perceptual field? And how are we to distinguish partial from complete spatiotemporalizations of consciousness? Recent speculations found in Paul Davies' The Mind of God (1992) provide possible answers.

Davies wrote that

The ability of quantum fluctuations to "fuzz out" the physical world on an ultramicroscopic scale leads to a fascinating prediction concerning the nature of space-time. Physicists can observe quantum fluctuations in the laboratory down to distances of about $10^{-16 t h}$ centimeters and over times of about $10^{-26 \text { th }}$ seconds. These fluctuations affect such things as the positions and momenta of particles, and they take place within an apparently fixed space-time background. On the much smaller Planck scale $\left[10^{-33 r d}\right.$ centimeters and $10^{-43 r d}$ seconds], however, the fluctuations would also affect space-time itself. $(1992$, p. 62$)$

Davies noted that 
The theory of relativity requires that we view three-dimensional space and one-dimensional time as parts of a unified four-dimensional space-time. In spite of the unification, space remains physically distinct from time. We have no difficulty in distinguishing them in daily life. This distinction can become blurred, however, by quantum fluctuations. At the Planck scale the separate identities of space and time can be smeared out. (1992, pp. 62-63)

Davies then observed that "the most probable structure of spacetime under some circumstances is actually four-dimensional space" (p. 63). When we reach the Planck scale, he noted, "Time begins to 'turn into' space" (p. 63).

Davies provided us with a yardstick to estimate what the length of this fractional extension should be. We can now speculate that this extension, to mind/body awareness, approaches but does not exceed a length of $10^{-33 r d}$ centimeters. But what are we presuming to measure? Is it an extension of consciousness stretching downward, from the ordinary scale of human perception, into infinitesimal reachers of the physical world? Or are we dealing with an expansion of consciousness up out of the three-dimensional world? Paradoxically, or so it seems, we are measuring both at the same time. The measurement, then, leads us both downward, into the depths of the physical universe, and upward toward the fourth dimension. The geometrical particulars of this process are uncovered in the scaling up from lower into higher dimensions, as formulated by Benoit Mandelbrot (1977). To begin to appreciate all of this, let us briefly consider the rationale underlying the process of fractional or, as Mandelbrot preferred, "fractal scaling." We will then apply these principles to the present model.

The coastline of England, viewed by human eyes from several thousands miles above, possesses the geometrical properties of a simple curve or one-dimensional line. However, what would happen if this coastline were examined from this height with a camera capable of clarifying this view? With each increase in the camera's resolution, the coastline's curves would become more complex, detailed and irregular in shape. It is logically feasible, and mathematically correct, Mandelbrot determined, to assign sufficiently complex curves a fractal value of more than one dimension. For instance, a coastline examined under sufficient resolution could take on a geometrical value of 1.26 dimensions or 1.38 dimensions.

In fractal geometry, the more complex and irregular such a curve is determined to be, the further away it is from its customary linear 
value-and the closer it comes to being two-dimensional. Sufficiently complex lines may actually take on the geometrical properties of the surface, that is, exhibit the contours of a two-dimensional plane. A one-dimensional or curvilinear continuum may eventually "smear out" such that this line merges completely into the plane that had been embedding it. In Mandelbrot's view, then, the dimensional status of a geometrical entity is determined by the distance between the observer and this entity, or by the observer's powers of observation. Geometrical entities, such as points, lines, and planes, do not, as in Euclidean geometry, possess absolute dimensional values; rather, these values are relative. And the same general principles apply to all fractal scalings between lower and higher dimensions, rather than just to those involving scalings up from one into two dimensions.

Let us now take the comparable case of a human being and examine what happens during the scaling up of $\operatorname{mind} /$ body awareness from three into four dimensions. At the physical end of this fractal continuum, an experiencer's awareness is confined to three dimensions: in normal "waking" consciousness, that person identifies himor herself to be three-dimensional. However, I have already argued that this identity is actually illusory, relative to a higher, four-dimensional reality level. The three-dimensional self in "waking" consciousness is actually a four-dimensional being dreaming that he or she is three-dimensional.

As the higher self begins to awaken, the experiencer's "body sense" begins to change. Markedly greater powers of internal awareness emerge and the "inhabited" three-dimensional organism comes under increasingly greater scrutiny. The awakening four-dimensional selfbegins to feel, and otherwise sense, the operation of energies within this "dream body." Awareness stretches down to encompass energetic activities occurring at the cellular, the molecular, the atomic, and then the subatomic level. This increased awareness of internal bodily energies, we can speculate, may be associated with the activation of what has come to be called "kundalini energy."

But what happens, then, when the reach of a person's mind/body sense stretches down past the Planck length? That person's consciousness spatiotemporalizes completely. The physical world "dreamer" merges into his or her fully awakened four-dimensional self, and that higher self utterly transcends the three-dimensional world. Such a voyager might encompass the whole of his or her world-line "time body" simultaneously, as if from eternity. That per- 
son's higher self might even animate this "time body" and move, within it, through hyperphysical realms of heavenly splendor. During complete expansions, the three-dimensional world of sensory experience loses all substance, relative to the higher reality level informing that experiencer's consciousness. All that is tangible in this world evaporates into shadows, viewed from eternity.

Eschatological possibilities such as these lie beyond this paper's focus. I mention them merely to intimate something of this theory's wider reach.

\section{Psychic Wanderings Between the Mystical and the Mundane}

To model separation experiences, our attention remains on partial or incomplete expansions. These fractional expansions stretch a person's mind/body awareness down close to, but not beyond, the Planck length. During partial expansions, an agent to be termed the mobile center of consciousness is activated. This term, though not the underlying construct, is borrowed from Andrija Puharich's (1960) field theory for psi. (While field theories for psychic experience could be described as "cousins" to hyperspace theories, they lie outside this paper's scope.)

Such a person now occupies a fractionally dimensioned world-line segment that is more than three- but still less than four-dimensional. The mobile center possesses an infinitesimal extension reaching out toward the "past" and "future" of that experiencer's three-dimensional space-along the world-line. The four-dimensional self of such a person now hovers between sleeping and waking. In such circumstances, we would expect that an experiencer's sense of simultaneity would slow down or enlarge. This is because the mobile center occupies a wider world-line slice and thus an expanded "present moment." Interestingly, the "time sense" is typically reported to slow down or elongate during OBEs and related ecstatic experiences (Green, 1968; Irwin, 1985).

Because the mobile center is slightly larger than the three-dimensional cross-section embedding "ordinary" consciousness, the awareness of those so embodied is no longer confined exclusively to the physical world. An experiencer may perceive what is taking place outside this reality slice. That person's mobile center may break loose from the three-dimensional moorings confining him or her to the 
lower world. Such a voyager may now range up and down along his or her world-line and begin to explore hyperspace, in fractionally dimensioned increments.

Such movement along the world-line may be said to extend in either one of two directions. Later, this stipulation will be modified for good reasons. For now, however, it may be said that this mobile space/time agent can shift through portions of four-dimensional space existing either in the "past" or "future" of the "present moment" out of which that voyager has shifted.

What would happen if this mobile space/time agent collapsed inward, losing its added dimensionality, during the midst of such an excursion? That voyager's consciousness would merge into whatever past or future "three-dimensional reality slice" he or she was intersecting at the point of collapse. And that past or future "self" might be stimulated by what, for him or her, would be nothing more than a memory or a premonition. Unless this mobile agent returns to the three-dimensional reality slice from whence it came, that voyager will have little or no memory of the journey. This view is quite compatible with the common psychic belief that we all engage in space/time sojourns on a regular basis while sleeping. Only rarely, if ever, do we remember these "psychic dreams." They are lost in the depths of what pioneer psychical researcher F. W. H. Myers (1903) called the "subliminal self," of which our conscious mind forms only an infinitesimal sliver. Much of what Myers conceived the "sublimal self" to be may be identifiable with the fully awakened four-dimensional self.

In this paper, however, our principal concern remains with the partially awakened higher self housed within the mobile center. What, then, do the space/time wanderings of this fractionally dimensioned agent have to do with the specific characteristics of separation experiences?

\section{The Operating Principles Underlying Separation Experiences}

How do we interpret separation experiences hyperspatially, within this context? Why do some experiencers actually feel this body separation while others spontaneously find themselves to be floating out of their physical bodies with no awareness of the transition? Why do yet others first pass through a dark tunnel or enclosed space before finding themselves "out-of-body"? And why, we might wonder, do 
"inside OBErs" so commonly perceive the scene from ceiling heights, in particular, from corner ceiling positions? And most importantly, from a hyperspatial point of view: Why do so many ecstatic voyagers report existing at very specific locations outside their physical bodies, but still inside three-dimensional space?

The shifting of consciousness conjectured above, along fractionally dimensioned world-line segments, is vitally significant to the creation of both "separation" and "tunnel passage" sensations. To unravel these and related mysteries, we must isolate and identify two additional factors. The second factor is the four-dimensional alignment of the ecstatic voyager's world-line body, at the onset of ecstasy. Is it, for example, positioned at right angles, or on a slant, or twisted or curved in some other fashion, relative to the three-dimensional reality slice out of which the voyager is shifting? The third factor is the possible four-dimensional movement of such segments during this shifting. To model separation experiences specifically, we are, of course, concerned with such movements and shiftings as they relate to world-line segments that are very close to the three-dimensional reality slice being left behind. The positions occupied during such shiftings are oftentimes so close, I would submit, that they practically entice ecstatic voyagers to participate in the illusion that they themselves are still inside three-dimensional space-minus a physical body.

We must accept one additional premise to bring this theory to life. During the initial stages of ecstasy, ecstatic voyagers almost always fail to perceive the fourth dimension. As Myers (1903, Vol. II, p. 277) once observed: "Just as the baby fails to grasp the third dimension, so may we still be failing to perceive a fourth." Recent evidence supports Myers' view on the deficiencies of infant perception. As Michael Guillen (1983) noted:

Psychologists have learned that infants crawling on a glass floor will not hesitate to crawl past the edge of a steep cliff. They are not afraid of heights because they apparently do not perceive height; theirs is a strictly two-dimensional world, and only when they have developed further are they able to perceive the world more correctly. (pp. 81-82)

Similarly, we may speculate that although the mobile center's visual field enables ecstatic voyagers to see in more than three dimensions, ecstatic voyagers have yet to learn to access these wider horizons. At the beginning of their ecstasies, especially, they unconsciously attempt to "squeeze" their extradimensional perceptions into 
a single three-dimensional reality slice. This is because they are conditioned, by physical existence, to frame perceptions three-dimensionally. They do not, in other words, perceive the depth quality in four-dimensional space. However, the environment they have entered will not conform entirely to their three-dimensional expectations. The four-dimensional properties of space emerge in variously disguised and distorted fashions, as found in numerous accounts of ecstatic voyagers. I will identify and analyze a sampling of the resulting perceptual effects through the remainder of this paper.

Properly appreciated, they become the foundations for the present theory. In other words, these effects reveal an underlying structure that bears a hyperspatial imprint. And, it is the recognition of this structure that illuminates the true meaning of ecstatic experiences. This, at least, is the paper's central thesis.

To fully appreciate these arguments, it is first necessary to understand that separation experiences are hyperspatial illusions. However, while separation experiences are, in and of themselves, "unreal," paradoxically they open up ecstatic voyagers, potentially, to levels of consciousness that are "more real than real." Once again, an inability to perceive depth in four dimensions masks what is actually taking place during the initial, fractionally dimensioned, transition into hyperspace.

J. H. M. Whiteman $(1961,1986)$ has argued similarly, in developing his related notion of "non physical spaces." Unfortunately, Whiteman was vague about the dimensional relationship between these nonphysical spaces and physical world space. This kept him from proposing a clear-cut explanation of how ecstatic voyagers interact paranormally with the physical world.

\section{Passing into Dimensions Unseen and Looking Back}

Imagine that an experiencer's world-line body is positioned at perfect right angles to the reality slice-and body-out of which the shift is to occur. Let us assume that the mobile center becomes activated during a partial awakening of the higher self. What would the experiencer perceive if this mobile agent moved a minimal distance into the fourth dimension and then became stationary? Let us assume that this agent moved a few inches, or even several feet, either 
in a "past" or "future" direction outside the experiencer's "present moment."

We must remember that this movement is only in a four-dimensional direction extending at right angles to the experiencer's threedimensional space. All other spatial orientations remain essentially the same, save one. The experiencer's fractionally dimensioned eyes and body possess enough extradimensional freedom for him or her to turn back slightly and look down into the lower space being left behind. How, then, would an experiencer "perceive" this slight extension into hyperspace while his or her extradimensional eyes visually tracked this movement? This person would be visually unaware of any movement. In the following analogy and discussion, let us see why this is so.

In Figure 1, a sentient two dimensional being's consciousness shifts up into a fractionally dimensioned position, outside its plane. This position is congruent, that is, it is evenly lined up at right angles to the lower space-and body-out of which this being's consciousness has shifted-with one exception. This being's fractionally dimensioned eyes and body possess enough extradimensional freedom to turn back, ever so slightly, so that it may look down into the lower space left behind. Where does this being place itself when so looking? It is conditioned not to perceive the depth quality in three-dimen-

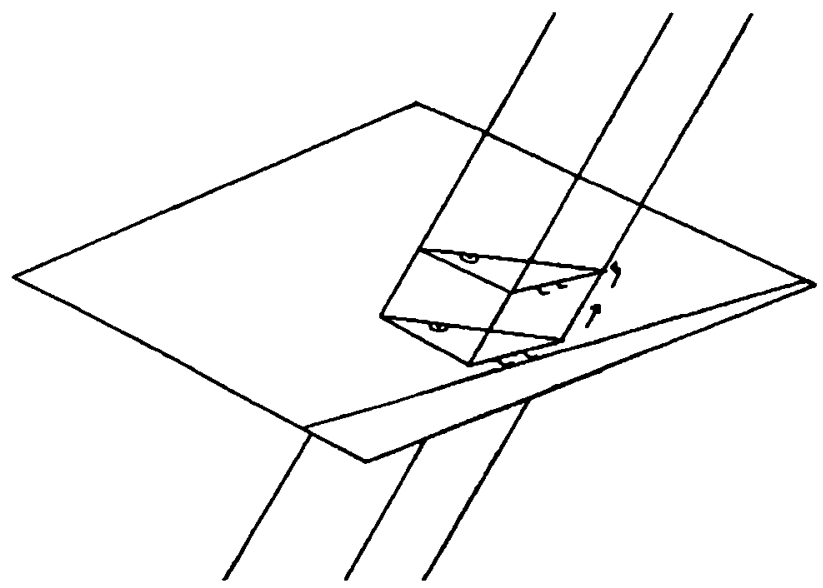

Figure 1. 
sional space. This depth, which measures the distance between this being's three-dimensional position and its two-dimensionally embedded body, remains unseen.

In a perceptual sense, this being unknowingly collapses the distance separating its three-dimensional position above the plane from that of its "lower body" embedded in the plane. And because it has no conception of the third dimension, it automatically uses the lower dimension as a reference point when attempting to perceptually assimilate the experience. Unless additional higher space factors come into play, this being never realizes that it has passed into a higher dimension. However, while this being does not visually register this "invisible movement" into a "dimension unseen," it might be able to sense something else about this shifting of positions. This being might feel strange wind-like energies rushing across what it perceives to be its "stationary" two-dimensional body, as its mobile center unknowingly shifts out of and looks back into the plane.

Similarly slight extradimensional movements, in conjunction with similarly angled spatial and bodily alignments, between three and four dimensions, would produce similar perceptual effects in us. Human beings undergoing this same "minimal movement" into a higher space would also fail to visually register any change in their apparent location. This assumes, of course, that their fractionally dimensioned eyes continue tracking the lower space out of which they are shifting. Their perceptual field would fail to take in "depth" at the four-dimensional level. Perceptually speaking, they would unknowingly eliminate the distance in hyperspace separating their actual position from that of their physical body. Thus, they would locate themselves to be still inside this lower body. The widely reported vibrations and sensations of energy rushes passing through experiencers' physical bodies at the outset of ecstasy are the only traces of such "invisible movements" and "backward glancings" they might register.

Let us now consider another case. What would happen if such a right-angled movement did not stabilize into motionlessness (relative to the lower dimension) just off the "edge" of that experiencer's threedimensional reality slice? Let us, rather, imagine that this extradimensional shifting and fractionally dimensioned movement continue, but with one additional difference. This time, the experiencer is not looking back at the lower space left behind. Such a voyager, we must remember, is no longer confined to a three-dimensional reality slice. Rather, he or she now occupies a mobile consciousness center possessing added dimensionality of some fractional value. The experi- 
encer's eyes, however, have yet to adjust to the more expansive spatial vistas and grander experiential realities becoming available for observation. Consequently, such a person sees nothing at all.

Sustained movement of this sort, along the cross-sections of worldlines, produces a common effect among ecstatic voyagers: the sense of passing through a long, dark tunnel. The more we examine the complexities of tunnel experiences in this context, I am convinced, the more sense the hyperspatial interpretation makes. One could liken tunnel experience passage to the act of leaving behind a very dark movie theater after a long movie, and being blinded by the light until one's eyes adjusted to daylight luminosity. This image calls to mind Plato's slave liberated after a lifetime chained underground: the sunlight continued to blind him for several days.

Let us now examine the hypothetical case of an NDEr whose experience was initiated by tunnel passage sensations. This experiencer then perceived him- or herself to be in the air a few feet above the physical body. Let us model this experience, analogically, with the diagram in Figure 2 and the following commentary.

This experiencer's mobile center passes along a fractionally dimensioned segment of his or her world-line a small distance into hyperspace. We are, once again, assuming that this world-line is positioned at right angles to the three-dimensional reality slice embedding the physical body. We are also assuming that the experiencer is not visu-

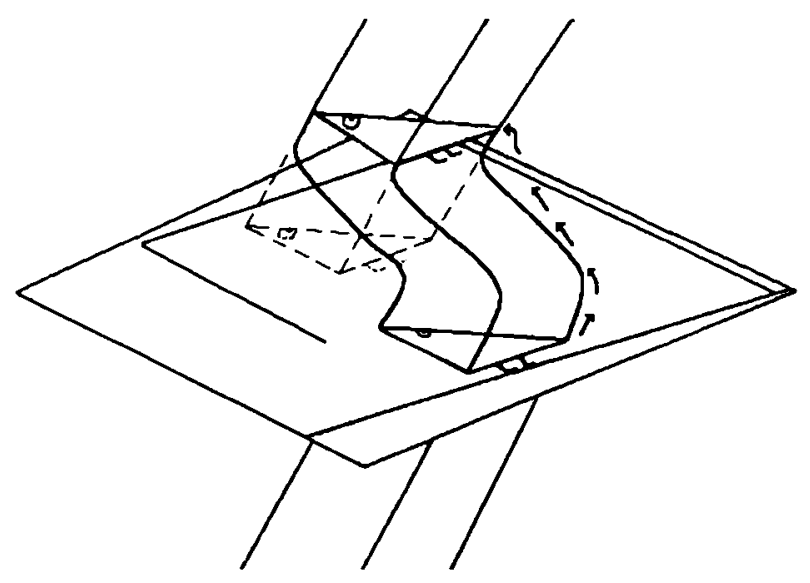

Figure 2. 
ally tracking the lower space. A few feet into hyperspace, however, the world-line veers off in a new direction positioned no longer at 90 degrees to the physical body's reality slice position. The voyager travels a little distance in this new direction, and then stabilizes into motionlessness, relative to the lower space. This experiencer's mobile center settles into a position that is congruent with the lower space out of which his or her consciousness has passed, at the same time, looking back into this space from the outside. What does he or she see? The voyager's four-dimensional position is no longer lined up directly above or outside the reality slice housing the physical body.

Where, then, does this experiencer place his or her locus of consciousness? Such a voyager is conditioned not to perceive the depth quality of hyperspace. When looking back, then, the distance traveled in this "invisible direction" fails to register perceptually. The experiencer unconsciously squeezes together his or her actual position in hyperspace with the position in lower space to which he or she is perceptually aligned. And knowing nothing of hyperspace, the voyager automatically uses the lower space as a reference point, when interpreting this exceedingly strange perceptual predicament. The experiencer's consciousness is thus projected down into the space he or she has left behind. The voyager identifies him or herself to be located at the position, in the lower space, that intersects the angle of projection from higher space. This position in the lower space, however, no longer coincides with the position of the body left behind. Instead, it happens, in this lower dimension, to be a few feet in the air above that body. Thus, the experiencer succumbs to the hyperspatially determined illusion that his or her consciousness is now floating in the air a few feet above the physical body.

Separation experiences initiated by tunnel passage sensations are rarely reported in the literature. Based on my informal sampling of cases drawn from approximately 70 books and articles devoted to the subject of OBEs, I estimate that they occur in less than 10 percent of all separation experience cases. Rather, tunnel experiences are usually reported to occur after completion of the initial separation experience. In approximately 75 percent of the separation experiences I have examined, experiencers report a sense of being "out-of-body" with no awareness of the transition. One moment, they are in their physical bodies; and the next they seem to be floating in the air above these bodies. How might we model such separations hyperspatially? The transition into hyperspace is much more gradual. The shifting is so slow, in fact, that experiencers do not register it until 
they spontaneously perceive themselves to be "out-of-body." Many individuals reporting this effect, we can surmise, were relaxing on their beds and half asleep. They were not, then, consciously focused on their spatial relationship to physical reality. And for a brief instant during the shift into hyperspace, their extradimensional eyes may not have been tracking the lower space out of which they were drifting.

Let us now hyperspatially model separation experiences in which ecstatic voyagers are fully conscious of the separation and subsequent sense of floating. Such an exit mode occurs in about 15 percent of the separation experiences I have studied. There is complete continuity in the experiencer's sense of spatial referencing, as he or she vividly feels the separation and elevation into the air.

The ecstatic voyager's world-line is positioned on a slant, rather than at right angles, to the physical body's three-dimensional reality slice. And from the start of this shifting, the ecstatic voyager is tracking this lower space. I have analogously modeled not only the final (apparent) position in the air above, but also the "floating transition" between the physical body and this (apparent) end position (Figure 3). Upon "reaching" the ceiling, after illusory passage through threedimensional space, the ecstatic voyager's consciousness stabilizes into relative motionlessness. During all of this shifting, the mobile consciousness center maintains enough visual contact and spatial continuity with the lower space to sustain the voyager's illusion that he or she has been in continuous "out-of-body contact" with this space.

\section{Separation-Experience-Related "Bodily Forms" and Feelings of Disembodiment}

Until now, we have only considered OBEs where the three-dimensional sides of ecstatic voyagers' mobile centers were congruent with the lower space out of which these voyagers had expanded. But what about those in which such sides are not so aligned? How would this change affect an ecstatic voyager's awareness of self and the surrounding "out-of-body" environment? Pondering this question opens up our inquiry to a new area of investigation: the study of "bodily forms" inhabited during OBEs, NDEs, and other ecstatic/dream/visionary experiences. I will now analyze commonly reported body feelings, and sensations of being disembodied, in light of this theory. 


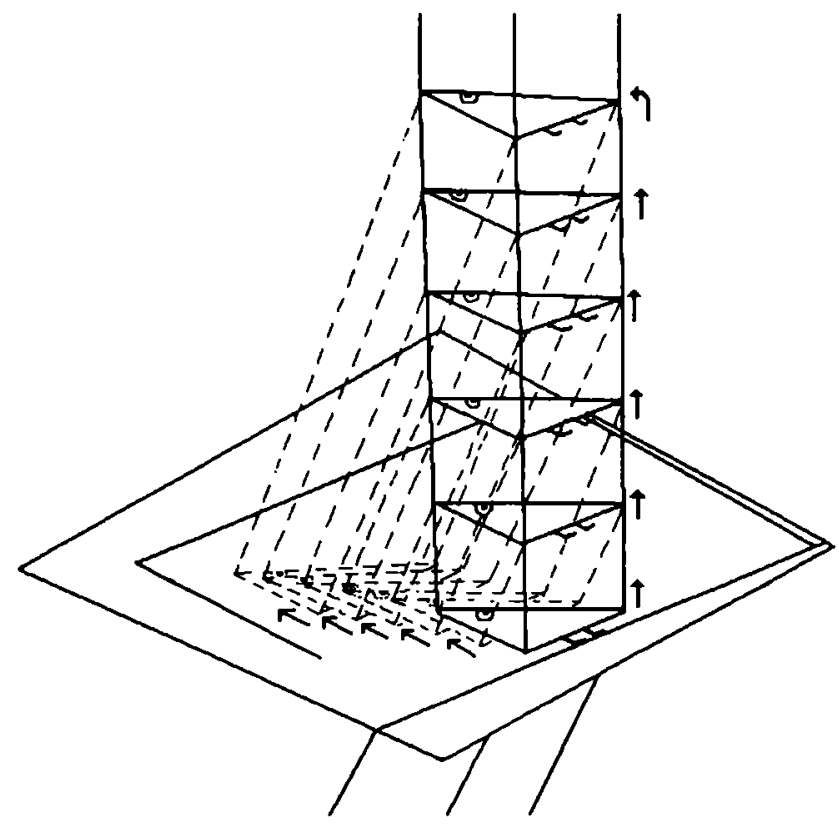

Figure 3.

The easiest out-of-body form to model is that of the "astral double." We have, in a sense, already stipulated the conditions under which this form manifests. A minimum of four conditions must be met and maintained to create and sustain "baseline" astral body sensations. First, the ecstatic voyager's mobile center must occupy a world-line slice that is "off edge," that is, not at a perfect right angle to the physical body reality slice position left behind. Second, the ecstatic voyager's extradimensional eyes must be tracking the lower space in question and he or she must succumb to the OBE illusions, that is, "project" his or her locus of consciousness down into that space. Third, the ecstatic voyager's mobile center must be motionless, relative to this lower space. And fourth, the ecstatic voyager's mobile center, or rather its three-dimensional side, must be congruent with this lower space.

These, then, are four of the five parameters that will, when modified, act reciprocally upon an ecstatic voyager's consciousness to produce changes in perceived bodily form. Modifying one or more of these variables changes the ecstatic voyager's sense of self-centeredness. These changes reach all the way from astral body sensations 


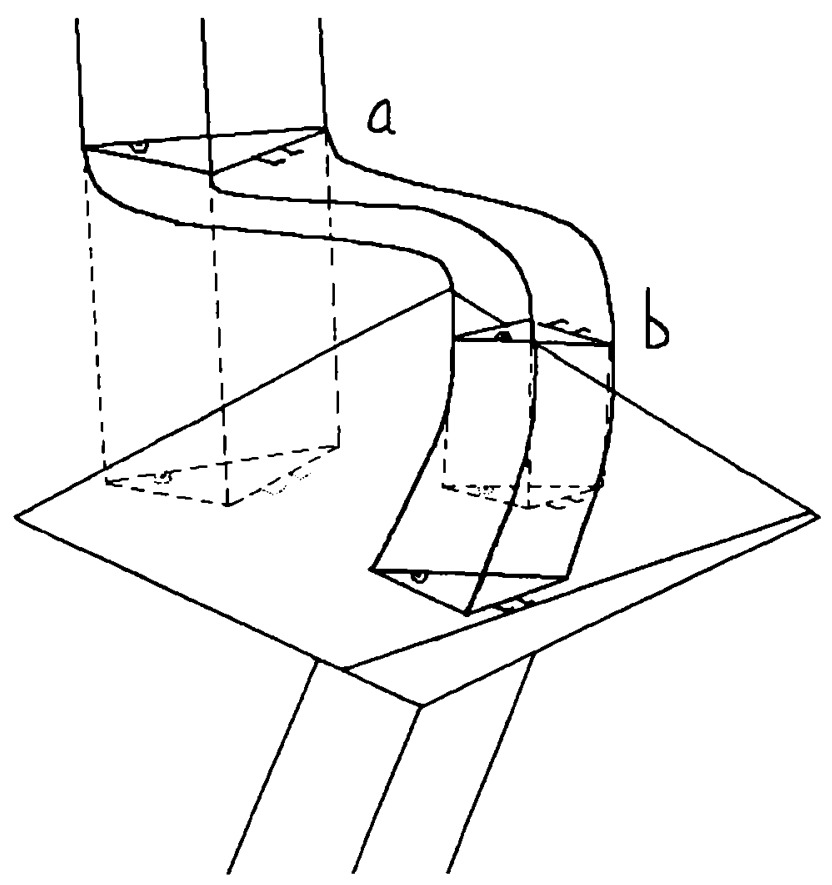

Figure 4.

closely resembling physical body feelings to sensations of utter disembodiment. A fifth variable plays a part in the production of other "body effects": if that portion of the world-line housing the mobile center moves relative to the lower reality slice, body feelings to be analyzed later in this section of the paper will be produced.

Let us now consider what "body effects" come into play when variable 4, the mobile center's congruence with the lower space, is modified. If the mobile center moves out of congruency with the lower space, the "astral body's" size and shape change accordingly. The resulting projection can expand or contract away from its original "duplicate form" parameters. Two factors, working together or independently of one another, determine the degree of alteration. The first is the changing of the angle by which the mobile center intersects its world-line. If the world-line segment housing the mobile center remains motionless (relative to the lower reality slice) during this reorientation, the "astral body" may contract in size. The resulting "body distortion" is illustrated in Figure 4 by the mobile center la- 


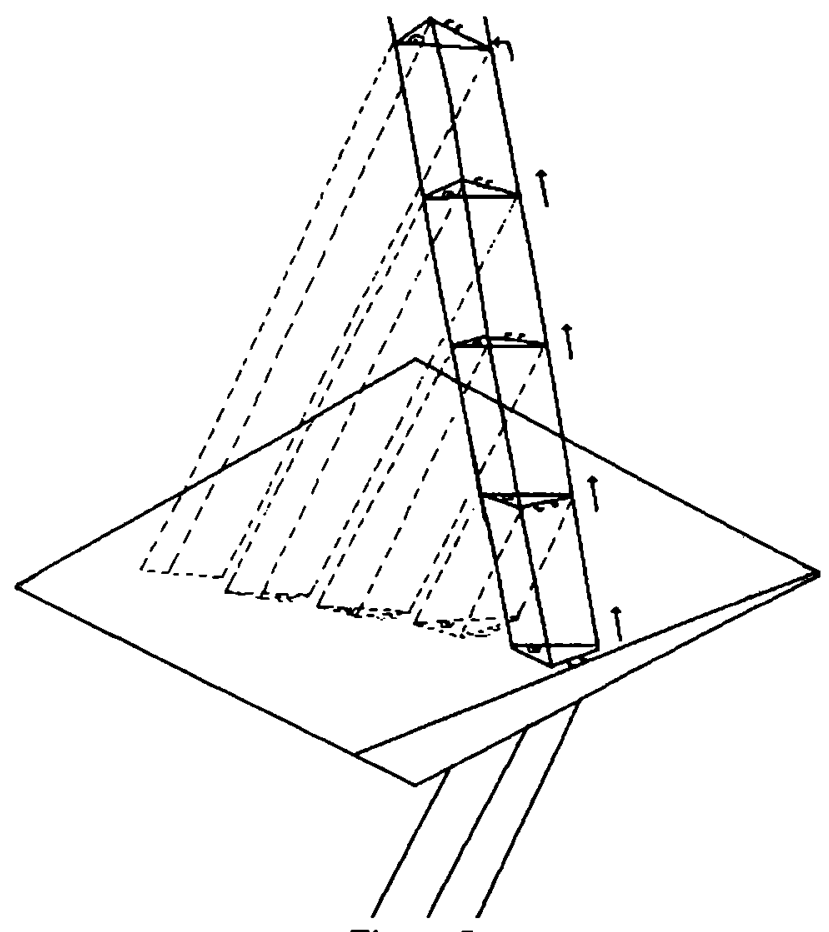

Figure 5.

beled $b$. If, however, the mobile center rotates such that it occupies a larger world-line slice, while the world-line itself moves, bringing this "larger" slice into congruency with the projection space, then the astral body will expand. The resulting "body distortion" is illustrated in Figure 4 by the mobile center labeled $a$.

In Figure 5 let us now examine, by analogy, the relationship between alterations in the astral body's size and feelings of disembodiment. The mobile center shifting into hyperspace rotates such that, eventually, its "three-dimensional" side is at complete right angles to the ecstatic voyager's projection space. The mobile center, presenting its four-dimensional "edge side," would melt away to nothing, relative to the lower space. One could argue that its astral body projection would disappear entirely from the voyager's "three-dimensionally conditioned" projection field. The voyager would sense that he or she was entirely disembodied but would still be perceptually locked into a specific location inside the lower space. This location would be cen- 
tered at the point, in the lower space, that intersected the projection angle from hyperspace.

An additional factor complicates this seemingly simple solution to the mystery of disembodiedness during OBEs. The ecstatic voyager's mobile center is more than three-dimensional. This center possesses some slight extradimensional extension, at right angles to its threedimensional extension, or the experiencer could not continue to exist in hyperspace. Yet the mobile center is still less than fully four-dimensional. This extension is of some fractional value between three and four dimensions. We have speculated that this extension approaches but does not exceed an increment of $10^{-33}$ centimeters added to the world-line's three-dimensional cross-section out of which the voyager emerged into hyperspace. We will now assume that this additional length is so minute that ecstatic voyagers fail to perceive it. Thus, they fail to include it in their lower dimensionally projected "sense of self." Instead, they succumb to the hyperspatially determined illusion that they are "disembodied." Considered any other way, I would argue, descriptions of occupying specific locations inside the physical world, while being disembodied, are unintelligible.

But what about globular forms, or feelings of occupying dime-sized areas, or even of having become a point of light? How might we model such self-perceived forms? In these circumstances, most of the ecstatic voyager's mobile center, or, more exactly, its three-dimensional side, has rotated out of alignment with the lower space. However, a small portion of this three-dimensional side remains congruent with the lower reality slice and thus remains visible within the voyager's "projection space." This is illustrated, analogously, in Figure 6. We see related instances in which a small portion of the ecstatic voyager's three-dimensionally extended mobile center remains congruent with the lower space while the preponderance is at right angles to this space. In the case of the mobile center labeled $b$, we see the area of a voyager's fractionally dimensional head remaining aligned with the lower space. Because the two-dimensional representations I am using are triangular, the resulting projection is a triangle. However, the fractionally dimensioned shape of a human head would more closely approximate that of a globe or sphere. The resulting projection would be, more or less, globular. In the case of the mobile center labeled $a$, we see an even smaller portion of its three-dimensional side remaining aligned to the lower space. This creates the sensation of occupying a "point-like" locus in the voyager's projection space. 


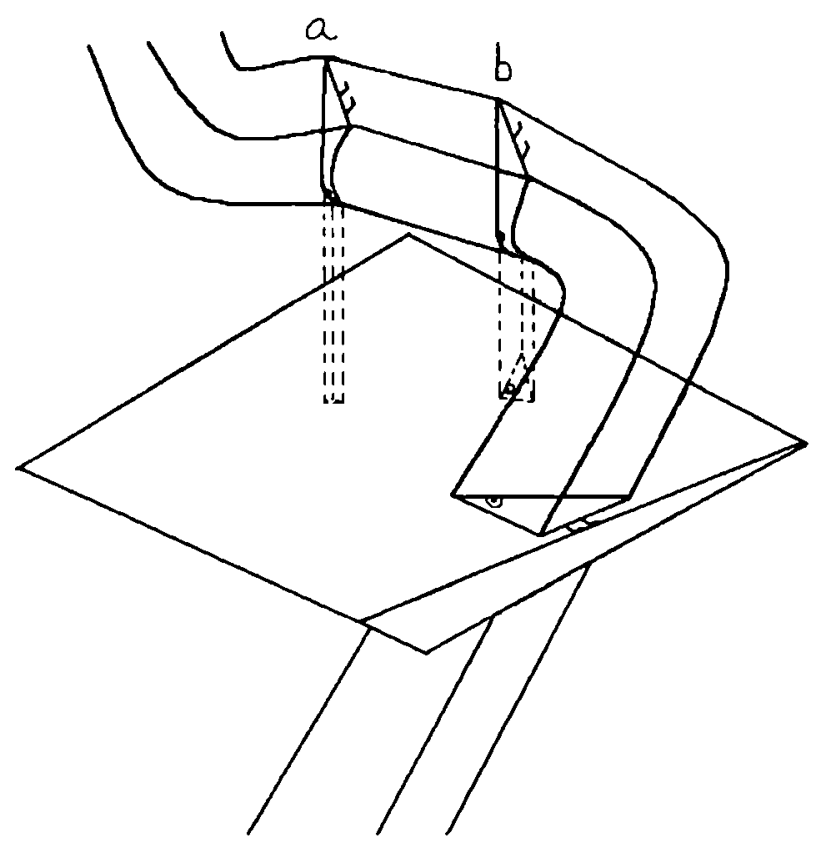

Figure 6.

Let us now consider other forms of embodiment during OBEs. How, for example, would we differentiate somesthetically the sense of inhabiting an astral body closely resembling the physical body, and the sense of inhabiting one possessing "fluidic properties"? The latter effect is produced in much the same way as are vibrations coursing across an experiencer's physical body at the outset of ecstasy. In other words, we would modify variable 3 , the mobile center's motion relative to the lower space. From the hyperspatial location locked into the $\mathrm{OBE}$ illusion, the ecstatic voyager's mobile center once again moves, ever so slightly, in a direction at right angles to the lower space in question. This is illustrated in Figure 7. This new movement, in the direction of the "invisible" fourth dimension, is depicted analogously in Figure 7. Such a further lifting away from, or moving towards, the three-dimensional reality slice would produce a sense of bodily motion without any accompanying visual recognition of movement. An ecstatic voyager, we must remember, is conditioned not to see the depth quality in four-dimensional space. Slight movements in a hyperspatial direction, once 


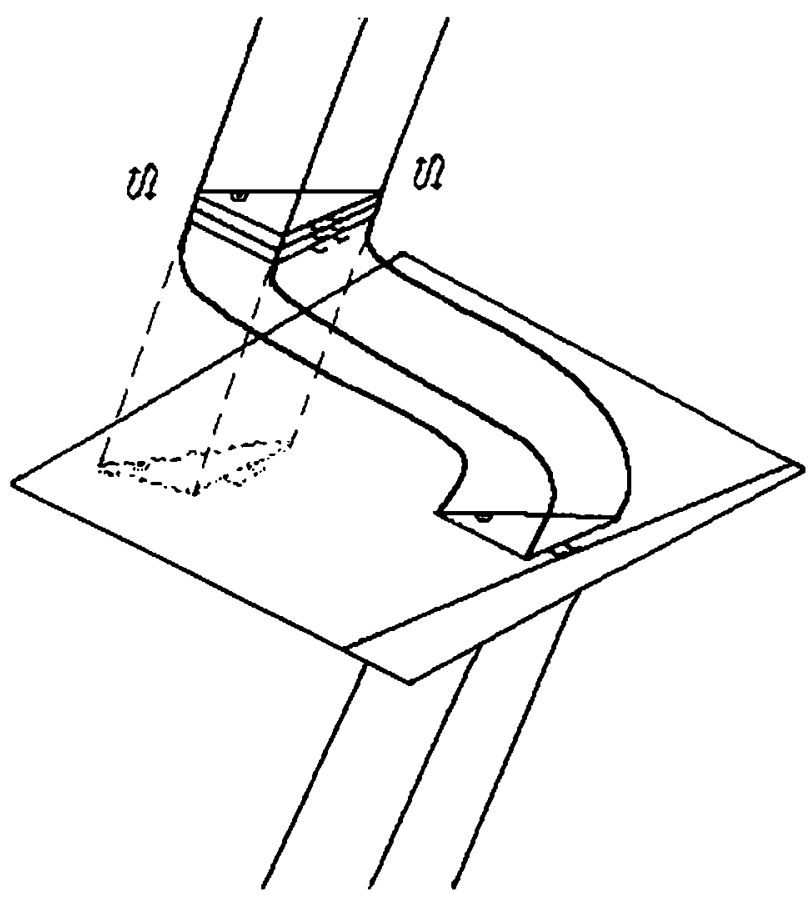

Figure 7.

again, would produce "body feelings" of subtle currents or vibrations, even though the voyager's sense of spatial location would remain visually unchanged.

Let us now consider what would happen were we to combine, into one complex motion, slight movements of the sort associated with variables 3 (the mobile center's motionless relative to the lower space), 4 (its congruence with the lower space), and 5 (its motion relative to the lower reality slice). Let us imagine that the world-line segment housing the mobile center is swaying back and forth, while the mobile center itself is bobbing up and down at right angles to the lower reality slice. Furthermore, let us suppose that this mobile center is tilting back and forth, or wobbling, relative to its world-line. I have illustrated this complex motion in Figure 8 by selectively combining ideas illustrated and/or discussed above. Were these three "holding patterns" in hyperspace combined into a more complex but partially stabilized motion, it would be very difficult for ecstatic voyagers to lock their body sense into a specific location in their pro- 


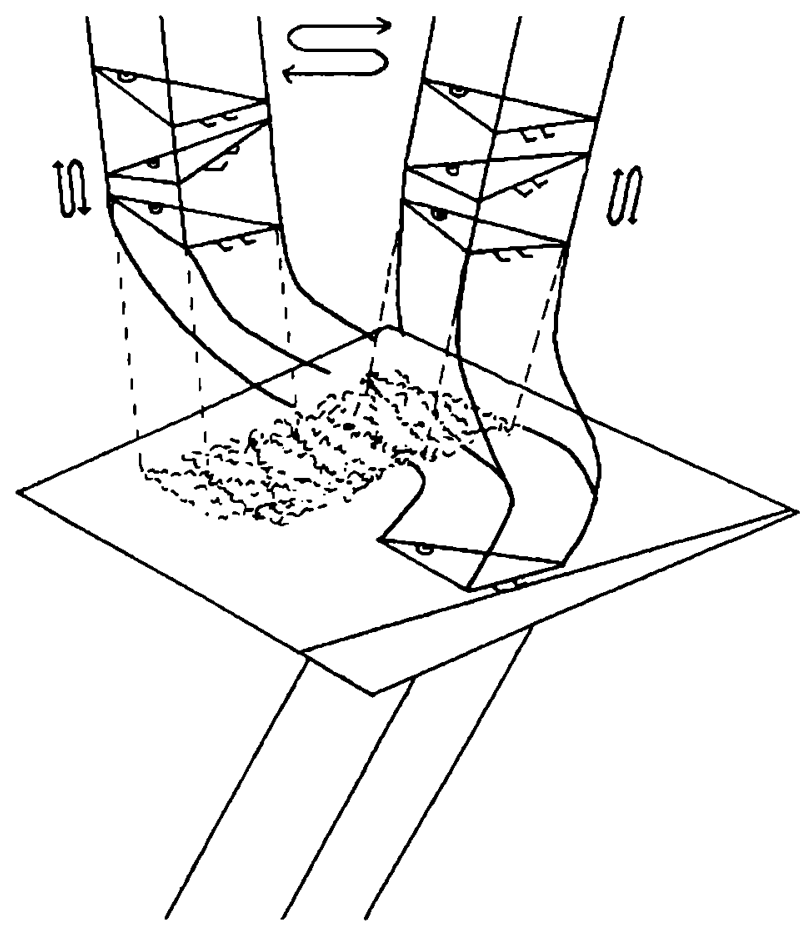

Figure 8.

jection space. The somesthetic response to this complex motion might be to create feelings of spatial diffusion, that is, a "field effect" on the experiencer's consciousness. Voyagers might conclude that they were "inhabiting" less tangible forms, such as gaseous clouds, mists, or energy patterns.

\section{Compromise “Corner Ceiling" Perceptions and Related Spatial Distortions}

Let us now examine in additional detail certain curiosities associated with "ceiling height" out-of-body perspectives. Upon a cursory analysis, these perspectives would seem unrelated to hyperspace. However, within a hyperspatial context, they become "compromise perceptions," bearing a hyperspatial imprint. To understand why, let 
us first consider, by analogy, how four-dimensional beings might perceive the scene inside a typical room in three-dimensional space in Figure 9. As inhabitants of the third dimension, we are able to see every linear contour of every hypothetical two-dimensional figure existing inside this room, all in a single glance. Sentient two-dimensional beings in this room, of course, could see linear sections of any figure whose perimeters were reflected within their "plane-bound" visual fields. For example, the two-dimensional being holding the square in Figure 9 could see no more than two of this square's four exterior sides from any particular viewing angle in the plane. This is analogous to our inability to see more than three of a cube's six sides at any particular moment, or from any one point of view, inside three-dimensional space.

Now, what would a four-dimensional being see when looking at a similarly contoured three-dimensional arrangement of space as if from the outside? One could argue that a truly existing four-dimensional being would only be privy to those things truly existing within a four-dimensional world. But just as we can imagine and easily visualize the properties of a hypothetical two-dimensional space as if from the outside, so too could four-dimensional beings do likewise with a "hypothetical" three-dimensional space. A four-dimensional being could effortlessly imagine, in vivid detail, every surface, exterior and interior, and all the space in between, of every three-dimensional solid in such a scene, all in a single glance.

OBErs rarely describe such all-encompassing vistas of the threedimensional scenes before them. Does this finding call into question

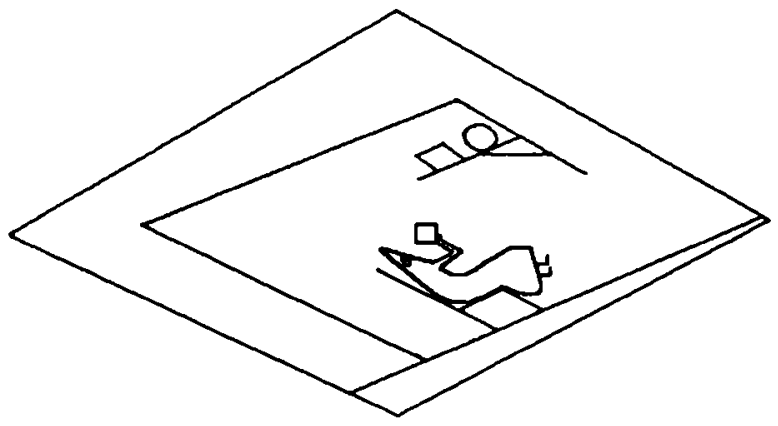

Figure 9. 
the four-dimensional theory for ecstatic experiences? No, it does not, because ecstatic voyagers, hovering just off the edge of three-dimensional reality, exist in a twilight zone between dimensions. Thus, the structures of their ecstatic visions are partially three- and partially four-dimensional.

What does all this have to do with determining the dimensional status of "corner ceiling" perspectives? From the corner ceiling, more of the room's surface area is available for viewing in a single glance than from anywhere else in the room. Of all the possible views in the room, the corner ceiling one is the most comprehensive. The view of space from this locus, more than from any other, comes closest to approximating the expansiveness of vision that would be available to four-dimensional beings. Corner ceiling positions are so commonly "occupied" by OBErs, then, because these positions serve as the natural point of contact between space and hyperspace. Corner ceiling perspectives bring vision of the lower space into sharpest focus for fractionally dimensioned observers in hyperspace. Thus, ecstatic voyagers, "looking back" at the space left behind, tend to settle into world-line segments that are angled on corner ceiling positions in the lower space.

Let us now consider a curious OBE anomaly associated with ceiling heights, whose existence further strengthens the hyperspace argument. In the majority of "ceiling height" cases, it is plausible to suppose that ecstatic voyagers have extended no more than 8 to 10 feet into hyperspace before stabilizing outside the reality slice left behind. This distance is approximately the same as the typical height that ceilings actually do extend in "visible" space. There is, then, nothing abnormal about ceiling height positions reported by the majority of ecstatic voyagers. Figure 2 demonstrates how hyperspace theory models such perspectives. The ecstatic voyager's actual extension into hyperspace, analogously depicted, is not much further, if at all, than the distance between the experiencer's physical body and the "ceiling height" projection.

Until now, the confirmed extrasomaticist might have little trouble holding onto his or her "objective" belief in the existence of a "separable soul." This is the belief parapsychologists failed to confirm, that separation experiencers somehow "invisibly" occupy positions inside three-dimensional space separate from their physical bodies.

However, the following category of "ceiling height" perspective seriously challenges such a view. To the best of my knowledge, Celia Green was the first researcher to make note of these curious cases 
and one of the very few to comment on them. She observed that in a minority of OBEs, "the subject may appear to be viewing things from a height greater than that of the ceiling, although the ceiling still seems to be above him" (1968, p. 41). One of her OBE subjects reported that "Although I seemed near the ceiling, the scene I have described seemed to be quite far away, as if I were actually in a higher position than that" (Green, 1968, p. 41). Another reported that "I, or my seat of consciousness, seemed to be hovering above my body at a height of perhaps 8-10 feet, which would have meant that my normal body would have been halfway through the roof" (Green, 1968, p. 41).

Such "above ceiling height" effects have been reported not only by Green's OBE subjects but also, in more recent years, by NDErs. One experiencer reportedly found herself "about fifty feet above ther hospital bed], which was physically impossible because the ceiling wasn't that high" (Harris and Bascom, 1990, p. 23). Yet another said:

The next thing I realized ... .I was very high up on the ceiling, looking down at myself. I looked very small. I seemed to be very high up, but I was still in the confines of the hospital room, looking down at my body. (Harris and Bascom, 1990, p. 209)

How are we to interpret experiences where the "perceived" height of the ceiling is so much higher than its actual height in the visible three dimensions? Where does this additional height come from? I can think of no simple solution to this problem for those who continue clinging to a simplistic extrasomatic view. However, the answer is obvious and straightforward, when these "elongated ceilings" are hyperspatially examined.

Ecstatic voyagers have traveled an appreciably greater distance into hyperspace than 8 or 10 feet before stabilizing into motionlessness at "ceiling height" positions. This is modeled analogously in Figure 10. Such voyagers have actually traveled two or three times as far, or even farther, in this "invisible direction" than the distance to the ceiling in visible space. When attempting to make sense of all this, they simply add the additional distance to their "pseudo-threedimensional" perceptual field. This occurs unconsciously and automatically, as they are projecting their viewpoint onto a "ceiling height location" in the lower space. In a sense, they have compressed a hyperspatial experience into three dimensions, by psychologically "stretching" the lower space. 


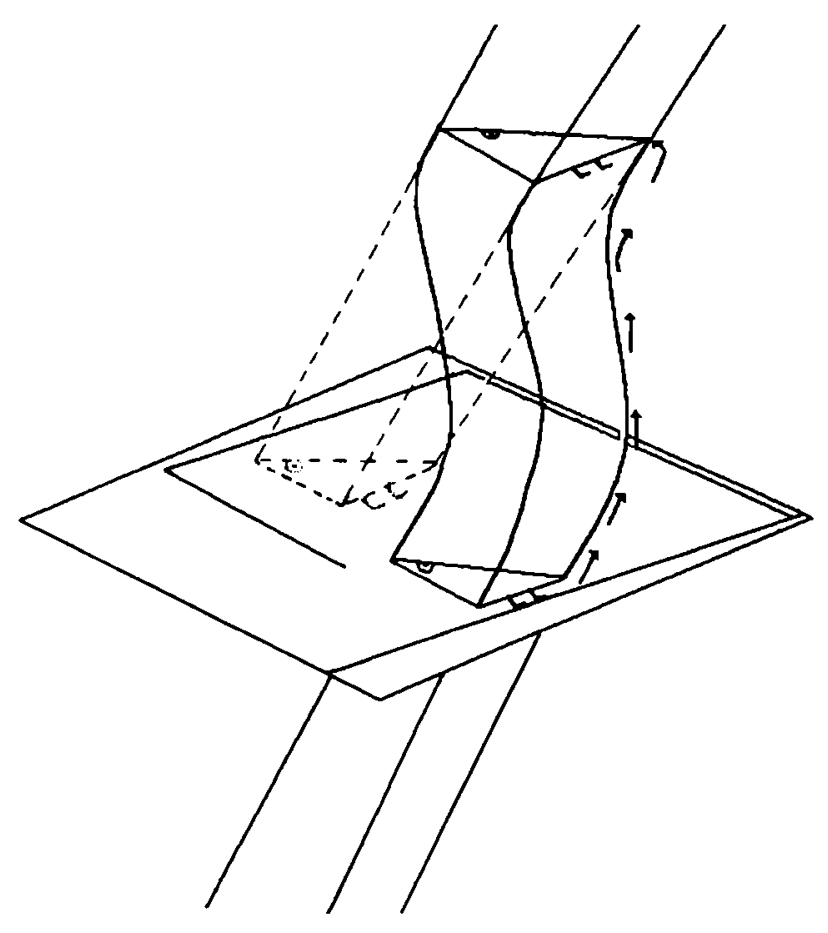

Figure 10.

\section{Implications of the Theory}

Let us now shift our attention from the hyperspatial diagramming of separation experiences to the implications that would follow, were this theory found to be correct. Parapsychologists failed to detect evidence of "astral bodies" in the laboratory on a systematic or predictable basis, for a simple reason: they were looking in the wrong place. Like their animistic forebears, they suspected that quasi-material "ghostly bodies" somehow inhabited the physical universe. Little of scientific value was gathered because parapsychologists were grasping at the shadows of higher dimensional bodies. They were fooled by the same hyperspatially determined illusions to which many ecstatic voyagers had succumbed, because parapsychologists had, in fact, based their experimental designs on the reports of such voyagers. However, not all ecstatic voyagers have fallen equally into these illusions. As reported by George Gallup and William Proctor (1982), some voyagers reported that it was "as if" they has passed out of 
their bodies. They implied that such a description was as close as they could come to making sense of what otherwise would be a totally ineffable experience.

Hyperspace theory's view of separation experiences, then, is paradoxical. When something is labeled an illusion, the common inference is that this phenomena is conceived to be unreal. However, the present explanation turns this presumption on its head. The illusion is created when human expectations about the nature of reality clash with the actual structure of this higher extension to the cosmos. All of this takes place during the initial fractionally dimensioned transition into hyperspace. Labeling out-of-body sensations as illusory, then, does not necessarily mean that the accompanying experiences are entirely brain-dependent. Nor are they ontologically vacuous, as materialistic skeptics would have us believe (Alcock, 1981; Siegel, 1980). Rather, they are entranceways into consciousness states that are "more real than real." They are, more exactly, hyperreal, or at least approaching the hyperreal. Parapsychologists need not withdraw into psychological theories of OBEs just because those experiences possess certain illusory qualities. Hyperspace theory provides an alternative that is not only compatible with the reality of the paranormal, but actually illuminates the phenomenological richness of ecstatic experiences far more comprehensively, and exactly, than any purely psychological or purely extrasomatic theory of which I am aware.

Take, for example, hyperspace theory's method of diagramming the range of bodily forms and feelings of disembodiment associated with OBEs. From a cursory and unreflective analysis, one might easily conclude that these forms are so diverse and arbitrary that they might defy any attempt at rational explanation. Were one to assume that ecstatic experiences are ontologically vacuous, the conclusion that related bodily forms are also meaningless would seem an obvious inference. And yet there is an intelligible pattern underlying these forms and related feelings of disembodiment, as I have demonstrated with this projective geometry. To the best of my knowledge, no ecstatic voyagers have ever reported being housed inside a body shaped like a kitchen sink or a Christmas tree. The forms, however diverse, are finite. I have, as a matter of fact, more or less comprehensively listed the range of shapes ecstatic voyagers take on, as reported in the literature. And I have modeled these shapes with a degree of geometrical exactitude previously unconceived, while demonstrating the hyperspatial interrelationships existing between them all. 
In this paper, the present separation experience model has been contrasted with extrasomatic and psychological theories for the same. However, to argue that these three different approaches are completely distinct would be an oversimplification. They may actually be seen to converge at certain points and in ways going beyond the scope of this paper.

Let us now briefly examine how certain psychological elements factor into hyperspace theory. A consideration of these factors may explain the existence of the partial expansions this paper models. Why then, might there sometimes be an arresting or freezing of this expansion? Why do some voyagers appear to inhabit a "psychic space" between three and four dimensions? Why, in other words, are there sometimes multiple stages in this ascent? Why not one entirely seamless and complete process of hyperspatialization, in each and every case?

Fear of engulfment in states of mystical union, that is, fear of the loss of selfhood, may disrupt or at least temporarily arrest some expansions. Such concerns may underlie attempts to turn back on the lower world from without. Under these circumstances, there may be a willful effort, on the part of the higher self, to succumb to the "out-of-body" illusion. Falling into this illusion may be as close as the partially awakened higher self can come to remaining in the dream state of "waking consciousness." The OBE, in these circumstances, then, serves as a substitute for ordinary consciousness and as the last defense against full hyperspatial arousal. It serves in this role only so long as it takes the higher self to fall back completely into the dream state of physical reality. Ecstatic voyagers need not be conscious of this fear or of how it motivates their "out-of-body" return to the physical world. The entire process, in other words, may operate subliminally.

The scenario I have outlined integrates certain facets of the psychological approach into a hyperspatial framework. For example, one psychological theorist, John Palmer, proposed that

The OBE is triggered by a more-or-less discrete change in the person's body concept . . . . This change in body concept threatens the self concept, or sense of individual identity. . . . This threat, which is unlikely to be perceived consciously, activates deep unconscious processes ... that attempt to reestablish the person's sense of individual identity as quickly and economically as possible. (1978, p. 19)

The OBE, accordingly, is the form this attempted reestablishment sometimes takes. 
Similarly, another psychological theorist, Susan Blackmore (1982a, 1993) proposed that an OBE may occur in a person whose ordinary sensory/perceptual channels have been disrupted or have otherwise ceased to function normally. When that individual remains actively intent on receiving such stimuli, he or she may be particularly prone to undergo an OBE. Such a person's consciousness, then, may shift into any one of a number of alternate reality models constructed out of memory and expectation rather than sensory input. This shifting into a highly unstable OBE facsimile of the "real world" only lasts as long as it takes that person's consciousness to shift back into a "normal" sensory/perceptual mode.

But where are these mysterious inner spaces in which OBE dramas are presumed to unfold? And what is their relationship to the space of external reality? Answers to these questions lie outside the scope of psychological theories. This is because of the conceptual blinders worn by psychological theorists. Hyperspace theory, in contrast, is large enough and flexible enough to provide possible answers. At least some dreams and visions, then, may be products of fractionally dimensioned observations of hyperspace, as previous theorists have speculated (Hart, 1953; McKenna, 1992; Rogo, 1978c; Rucker, 1982; Smythies, 1967; Whiteman, 1961, 1968; Wolf, 1988).

When fractionally dimensioned observers in hyperspace lock onto the three-dimensional reality slice out of which their consciousness has shifted, a "discrete" OBE may be created. When such observers temporarily acclimate themselves to alternate three-dimensional reality slices nested in hyperspace alongside their "home space," other forms of ecstatic/dream/visionary experience may ensue. When they mistake a scene inside one of these alternate three-dimensional spaces for one in their home space, they might falsely conclude that they have acquired extrasensory knowledge of their home space. Such mistakes, then, account for the occasional "false perceptions" documented in OBE literature.

Apparitional encounters and "metachoric experiences," as recently analyzed by Green and Charles McCreery (1994), may also be modeled with a slight extension to hyperspace theory. The same may be said of Raymond Moody's (Moody and Perry, 1993) "middle realm" experiences. Those who encounter apparitions of departed loved ones and other anomalous entities, then, may be unaware that they have temporarily shifted out of their home space into a nearly identical parallel space. They will not even experience an $\mathrm{OBE}$, if their mobile center remains at perfect right angles to their "stay-at-home-body" 
during this shifting. They then return without ever imagining that they have left physical reality behind. The "imaginal realm" postulated by Ring (1990) and other consciousness researchers also fits into this same framework. To diagram dreams, visions, and other imaginal realm encounters in a conceptually sound fashion, we must extend our analysis from four into five or even six dimensions. Such an exercise lies beyond this scope of this paper.

Among psychological theorists, only Palmer made any reference to the hyperspatial implications of the ideas he was exploring. He observed that

the psychological theorist may be correct in his explanation of the $\mathrm{OBE}$ at a psychological level and yet eventually come to conclude, based on other kinds of evidence, that mind-body separation (whether in Euclidean or some kind of "higher" space) is a valid concept. (1978, p. 22)

Others, such as Jan Ehrenwald (1978) and Blackmore (1982a), have shown no awareness that their ideas could be hyperspatially framed.

\section{Hyperspace and the Paranormal}

Are all of the claims examined in this paper to be summarily dismissed because they are so hard to demonstrate experimentally? Or are we dealing with paranormal facets of human nature that are simply too unruly to be controlled adequately in the laboratory? Assuming, for the sake of argument, that the latter is true, why might this be so? Ecstatic voyagers, I would argue, are caught between two reality levels and only partially awake to either one. They are moving about in a world where their sense of depth perception is barely, if at all, functioning. This makes for highly disorienting experiences. These speculations become plausible when we consider the possibility that during such experiences voyagers sometimes shift into a fractional domain positioned between space and hyperspace. Hyperspace theory, examined within this context, thus offers a rational explanation for paranormal happenings linked to ecstatic experiences.

Let us now briefly consider a paranormal extension to these ideas. The easiest paranormal mystery to explain hyperspatially is that of local clairvoyance. Several of the figures in this paper provide insight into the hyperspatial modeling of clairvoyance. When hyperspatially tracking the lower space, the experiencer's range of perception of that 
space becomes vastly extended. Even just slight shiftings of the mobile center into hyperspace, combined with minimal world-line movements of those segments housing this center, can vastly extend a voyager's "lower space" awareness. However, to model "traveling clairvoyance" to more distant locations within the physical universe, the theory must be enlarged.

Earlier in this paper, I stipulated that his mobile agent could shift away from the voyager's three-dimensional reality slice, either into the "past" or "future." These movement limitations, I noted, were introduced as temporary measures, while introducing the theory. To model traveling clairvoyance, remote viewing, and OBE-related apparitions and bilocations, we must remove these constraints. (To a small degree, we already have, in elucidating the psychodynamics of experiences.) Portions of the experiencer's world-line, or hyperphysical appendages stemming therefrom, may also extend in directions other than at right angles to the voyager's lower reality slice. They may also extend in four-dimensional space along pathways lying parallel to, or even approaching, this lower space. Relativity theory may allow such world-line movements, called "closed time-like" curves in the parlance of contemporary physics. They have been written about extensively by Kurt Gödel (1949), and are detailed in Michio Kaku's excellent introduction to modern physics and cosmology appropriately entitled Hyperspace (1994).

The mobile center, shifting along portions of a world-line extension or appendage, could occupy world-line segments existing in local proximity to any possible geographic site on the Earth. From such a vantage point, a voyager could inspect clairvoyantly any scene or event occurring at that particular lower-dimensional site. Within this context, an apparitional sighting of such an ecstatic voyager would involve a partial or peripheral penetration of the world-line segment housing that mobile center, into the locality under inspection from hyperspace. A bilocation would involve a similar but more complete penetration into that lower space. Apparitional manifestations and materializations of ecstatic voyagers, then, do not constitute distinct categories of paranormal intrusions into the physical world from without. Rather, such incursions exist along a penetration continuum at the fractionally dimensioned interface between space and hyperspace. Related psychokinetic activity would involve physical contact between portions of the voyager's intruding "self" and portions of three-dimensionally extended matter under invasion from hyperspace. 
The same general theory accounts for all forms and degrees of phantasmal intrusion, rather than just for those in which "living agents" have paranormally visited "distant locations." Thus, we have the makings of a very broad theory for the paranormal, that is, a comprehensive mode of operation for psychic phenomena grounded within a paranormal extension to relativity theory. What is essentially the same conclusion for such phantoms was reached by Hornell Hart and associated collaborators (1956). However, not enough was known about ecstatic experiences at the time to integrate a hyperspatial understanding of separation experiences clearly into that broader framework. In the time since Hart's demise, more general information on ecstatic experiences has been gathered than in our planet's entire previous history. Another critical advance in human knowledge, highly pertinent to the paranormal use of hyperspace theory but unavailable to earlier researchers, has been the advent of fractional or fractal geometry.

What, then, does all of this mean? When the hyperphysical properties of human nature are uncovered and appropriately identified, as I believe this paper has started to do to some small degree, they reveal to us an extraordinary truth. They suggest that whatever else we may be, we are more than just three-dimensional troglodytes confined to a finite physical existence. Rather, they intimate that we are endowed with extradimensional capabilities enabling us to reach into multiple, perhaps even infinite, dimensions of space and time. We are, as spiritual sages have long proclaimed, beings of light slumbering through the remainder of this earthly night.

\section{References}

Alcock, J. E. (1981). Psychology and near-death experiences. In K. Frazer (Ed.), Paranormal borderlands of science (pp. 153-169). Buffalo, NY: Prometheus Books.

Alvarado, C. (1982a). Recent OBE detection studies: A review. Theta, 10(2), 35-37.

Alvarado, C. (1982b). ESP during out-of-body experiences: A review of experimental studies. Journal of Parapsychology, 46, 209-230.

Atwater, P. M. H. (1994). Beyond the light: What isn't being said about the near-death experience. New York, NY: Birch Lane Press.

Becker, C. B. (1983a). Out of their bodies or out of their minds? On the extrasomaticity of OBE's. Part I. Journal of Religion and Psychical Research, 6, 3-22.

Becker, C. B. (1983b). Out of their bodies or out of their minds? On the extrasomaticity of OBE's. Part II. Journal of Religion and Psychical Research, 6, 86-93.

Becker, C. B. (1993). Paranormal experience and survival of death. Albany, NY: State University of New York Press. 
Blackmore, S. (1982a). Beyond the body: An investigation of out-of-the-body experiences. London, England: Heinemann.

Blackmore, S. (1982b). Parapsychology-with or without the OBE? Parapsychology Review, 13(6), 1-7.

Blackmore, S. (1993). Dying to live: Science and the near-death experience. Buffalo, NY: Prometheus Books.

Bragdon, C. (1916). Four dimensional vistas. New York, NY: Alfred Knopf.

Bremmer, J. (1983). The early Greek concept of the soul. Princeton, NJ: Princeton University Press.

Broad, C. D. (1969). Mr. Dunne's theory of time. In C. D. Broad, Philosophy, religion and psychical research (pp. 68-85). New York: Humanities Press.

Capel, M. (1979). Possible forms of survival of death. Psi Comunicacion, 5(9-10), 25-33.

Couliano, I. P. (1991). Out of this world: Otherworld journeys from Gilgamesh to Albert Einstein. Boston, MA: Shambhala.

Cox-Chapman, M. (1995). The case for heaven: Near-death experiences as evidence of the afterlife. New York, NY: G. P. Putnam's Sons.

Crookall, R. (1960). The study and practice of astral projection. Secaucus, NJ: University Books.

Davies, P. (1992). The mind of God: The scientific basis for a rational world. New York, NY: Simon and Schuster.

Davies, P. (1995). About time: Einstein's unfinished revolution. New York, NY: Simon and Schuster.

Dunne, J. W. (1927). An experiment with time. London, England: Faber and Faber.

Eddington, A. (1958). The nature of the physical world. Ann Arbor, MI: University of Michigan Press.

Ehrenwald, J. (1978). The ESP experience: A psychiatric validation. New York, NY: Basic Books.

Gabbard, G. O., and Twemlow, S. W. (1984). With the eyes of the mind: An empirical analysis of out-of-body states. New York, NY: Praeger.

Gallup, G., and Proctor, W. (1982). Adventures in immortality: A look beyond the threshold of death. New York, NY: McGraw Hill.

Gamow, G. (1988). One, two, three . . infinity: Facts and speculations of science. New York, NY: Dover (Original work published 1957.)

Gödel, K (1949). An example of a new type of cosmological solution of Einstein's field equations of gravitation. Review of Modern Physics, 21, 447.

Green, C. (1968). Out-of-the-body experiences. London, England: Hamish Hamilton.

Green, C., and McCreery, C. (1994). Lucid dreaming. New York, NY: Routledge.

Greene, F. G. (1981). A glimpse behind the life review. Journal of Religion and Psychical Research, 4, 113-130.

Greene, F. G. (1983). Multiple mind/body perspectives and the out-of-body experience. Anabiosis: The Journal of Near-Death Studies, 3, 39-62.

Greene, F. G., and Krippner, S. (1990). Panoramic vision: Hallucination or bridge into the beyond? In G. Doore (Ed.), What survives? Contemporary explorations of life after death (pp. 61-75). Los Angeles, CA: Tarcher.

Grey, M. (1985). The return from death: An exploration of the near-death experience. London, England: Arkana.

Grosso, M. (1992). Frontiers of the soul: Exploring psychic evolution. Wheaton, IL: Quest Books.

Guillen, M. (1983). Bridges to infinity. Los Angeles, CA: Tarcher.

Harris, B., and Bascom, L. C. (1990). Full circle: The near-death experience and beyond. New York, NY: Pocket Books.

Harrison, E. (1984). The masks of the universe. New York, NY: Macmillan.

Hart, H. (1953). The psychic fifth dimension. Journal of the American Society for Psychical Research, 47, 3-32. 
Hart, H. (1954). ESP projection: Spontaneous cases and the experimental method. Journal of the American Society for Psychical Research, 48, 121-146.

Hart, H., and associated collaborators (1956). Six theories about apparitions. Proceedings of the Society of Psychical Research, 50, 153-239.

Hinton, C. H. (1904). The fourth dimension. London, England: Swann Sonnenschein.

Irwin, H. J. (1985). Flight of mind: A psychological study of the out-of-body experience. Metuchen, NJ: Scarecrow Press.

Kaku, M. (1994). Hyperspace. New York, NY: Oxford University Press.

Krippner, S., and Villoldo, A. (1976). Realms of healing. Berkeley, CA: Celestial Arts.

Lombroso, C. (1909). After death, what? Boston, MA: Small, Maynard.

Luttenberger, F. (1977). Friedrich Zollner, spiritualism and four-dimensional space. Zeitschrift für Parapychologie und Grenzgebiete der Psychologie, 19, 195-214.

Mandelbrot, B. (1977). The fractal geometry of nature. San Francisco, CA: Freeman.

McKenna, T. (1992). New maps of hyperspace. In T. McKenna, The archaic revival: Speculations on psychedelic mushrooms, the Amazon, virtual reality, UFOs, evolution, shamanism, the rebirth of the goddess, and the end of history (pp. 90-103). San Francisco, CA: Harper San Francisco.

McLaughlin, S. C. (1977). On feeling good: An operating manual for the human consciousness: Being a discourse on the high states of consciousness in relation to the fourth, fifth, and sixth dimensions, with special reference to the possibility of inner development, the value of esoteric knowledge, and the nature of time and immortality. Brookline, MA: Autumn Press.

McLaughlin, S. C. (1986). Dimensionality and states of consciousness. In B. B. Wolman and M. Ullman (Eds.), Handbook of states of consciousness (pp. 68-96). New York, NY: Van Nostrand Reinhold.

McMoneagle, J. (1993). Mind trek: Exploring consciousness, time and space through remote viewing. Charlottesville, VA: Hampton Roads.

Moody, R. A., and Perry, P. (1988). The light beyond. New York, NY: Bantam.

Moody, R. A., and Perry, P. (1993). Reunions: Visionary encounters with departed loved ones. New York, NY: Villard.

Murphy, M. (1992). The future of the body: Explorations into the further evolution of human nature. Los Angeles, CA: Tarcher.

Myers, F. W. H. (1903). Human personality and its survival of bodily death. London, England: Longmans, Green.

Nash, C. B. (1963). Physical and metaphysical parapsychology. Journal of Parapsychology, 27, 283-300.

Osis, K. (1978). Out-of-body research at the American Society for Psychical Research. In D. S. Rogo (Ed.), Mind beyond the body: The mystery of ESP projection (pp. 162169). New York, NY: Penguin.

Ouspensky, P. D. (1923). Tertium organum: A key to the enigmas of the world. London England: Longmans, Green.

Palmer, J. (1978). The out-of-body experience: A psychological theory. Parapsychology Review, 9(5), 19-22.

Powell, A. E. (1927). The astral body and other astral phenomena. Wheaton, IL: Theosophical Publishing House.

Price, H. H. (1939). Haunting and the "psychic ether" hypothesis: With some preliminary reflections on the present condition and possible future of psychical research. Proceedings of the Society for Psychical Research; 45, 307-343.

Price, H. H. (1953). Survival and the idea of "another world." Proceedings of the Society for Psychical Research, 50, 1-25.

Puharich, A. (1960). Beyond telepathy. New York, NY: Anchor.

Rauscher, E. (1980). Some physical models potentially applicable to remote perception. In A. Puharich (Ed.), The Iceland papers (pp. 49-93). Amherst, WI: Essential Research Associates. 
Renninger, M. (1977). An actually existent fourth dimension of space as a model for the explanation of psychokinetic phenomena? Zeitschrift für Parapsychologie und Grenzgebiete der Psychologie, 19, 215-226.

Ring, $K$ (1980). Life at death: A scientific investigation of the near-death experience. New York, NY: Coward, McCann, and Geoghegan.

Ring, K. (1982). Precognitive and prophetic visions in near-death experiences. $A n$ abiosis: The Journal of Near-Death Studies, 2, 47-74.

Rink, K. (1984). Heading toward omega: In search of the meaning of the near-death experience. New York, NY: Morrow.

Rink, K. (1990). Shamanic initiation, imaginal worlds, and light after death. In G. Doore (Ed.), What Survives? Contemporary explorations of life after death (pp. 204215). Los Angeles, CA: Tarcher.

Ring, K., and Lawrence, M. (1993). Further evidence for veridical perception during near-death experiences. Journal of Near-Death Studies, 11, 223-229.

Rogo, D. S. (1973). Man does survive death. Secaucus, NJ: Citadel Press.

Rogo, D. S. (1978a). Experiential aspects of out-of-body experiences. In D. S. Rogo (Ed.), Mind beyond the body: The mystery of ESP projection (pp. 43-51). New York, NY: Penguin.

Rogo, D. S. (1978b). Can we explain the out-of-body experience? Introduction: Conceptual models. In D. S. Rogo (Ed.), Mind beyond the body: The mystery of ESP projection (pp. 313-322). New York, NY: Penguin.

Rogo, D. S. (1978c). The out-of-body experience: Some personal views and reflections. In D. S. Rogo (Ed.), Mind beyond the body: The mystery of ESP projection (pp. 349362). New York, NY: Penguin.

Rosen, S. M. (1983). Paraphysical reality and the concept of dimension. Journal of Religion and Psychical Research, 6, 118-129.

Rucker, R. (1977). Geometry, relativity and the fourth dimension. New York, NY: Dover.

Rucker, R. (1982). Infinity and the mind; The science and philosophy of the infinite. Boston, MA: Birkhauser.

Sabom, M. (1982). Recollections of death: A medical investigation. New York, NY: Harper and Row.

Sharp, K. C. (1995). After the light: What 1 discovered on the other side of life that can change your world. New York, NY: Morrow.

Siegel, R. K. (1980). The psychology of life after death. American Psychologist, 35, 911-931.

Slawinski, J. (1987). Electromagnetic radiation and the afterlife. Journal of NearDeath Studies 6, 79-94.

Smith, W. W. (1920). A theory of the mechanism of survival: The fourth dimension and its applications. New York, NY: Dutton.

Smythies, J. R. (1967). Is ESP possible? In J. R. Smythies (Ed.), Science and ESP (pp. 1-14). London, England, Routledge and Kegan Paul.

Targ, R., and Harary, $\mathrm{K}$ (1984). The mind race: Understanding and using psychic abilities. New York, NY: Villard.

Tart, C. (1978). Paranormal theories about the out-of-body experience. In D. S. Rogo (Ed.), Mind beyond the body: The mystery of ESP projection (pp. 338-345). New York, NY: Penguin.

Tinoco, C. (1982). Apport phenomena and the nature of space. In Proceedings of the Third National Congress of Parapsychology and Psychotronics (pp. 29-39). Rio de Janeiro, Brazil.

Walker, B. (1974). Beyond the body: The human double and the astral planes. London, England: Routledge and Kegan Paul.

Wenzl, A. (1957). Dimensions of time. In Proceedings of four conferences of parapsychological studies (pp. 24-25). New York, NY: Parapsychology Foundation. 
White, J., and Krippner, S. (Eds.). (1977). Future science: Life energies and the physics of paranormal phenomena. Garden City, NY: Anchor Books.

Whiteman, J. H. M. (1961). The mystical life. London, England: Faber and Faber.

Whiteman, J. H. M. (1967). The philosophy of space and time. London, England: Allen and Unwin.

Whiteman, J. H. M. (1986). Old and new evidence on the meaning of life. Gerrards Cross, England: Colin Smythe.

Whitrow, G. J. (1972). What is time? London, England: Thames and Hudson.

Wilson, C. (1988). Beyond the occult. New York, NY: Carroll and Graf.

Wolf, F. A. (1988). Parallel universes: The search for other worlds. New York, NY: Simon and Schuster.

Woodhouse, M. B. (1990). Beyond dualism and materialism: A new model of survival. In G. Doore (Ed.), What survives? Contemporary exploration of life after death (pp. 122-137). Los Angeles, CA: Tarcher.

Zollner, J. C. F. (1881). Transcendental physics. Boston, MA: Colby and Rich.

Zohar, D. (1982). Through the time barrier: Precognition and modern physics. London, England: Heinemann. 